OPEN ACCESS

Edited by:

Danni Lei,

Sun Yat-sen University, China

Reviewed by:

Renheng Wang,

Shenzhen University, China

Xunhui Xiong,

South China University of

Technology, China

${ }^{*}$ Correspondence:

Hui Tong

huitong@csu.edu.cn

Specialty section

This article was submitted to

Electrochemistry,

a section of the journal

Frontiers in Chemistry

Received: 19 March 2019

Accepted: 25 April 2019

Published: 14 May 2019

Citation:

$L i H$, Zhang B, Wang X, Zhang J, An T,

Ding Z, Yu W and Tong H (2019)

Heterostructured $\mathrm{SnO}_{2}-\mathrm{SnS} \mathrm{S}_{2} @ \mathrm{C}$

Embedded in Nitrogen-Doped

Graphene as a Robust Anode Material

for Lithium-Ion Batteries.

Front. Chem. 7:339.

doi: 10.3389/fchem.2019.00339

\section{Heterostructured $\mathrm{SnO}_{2}-\mathrm{SnS}_{2} @ \mathrm{C}$ Embedded in Nitrogen-Doped Graphene as a Robust Anode Material for Lithium-Ion Batteries}

\author{
Hui Li ${ }^{1}$, Bao Zhang ${ }^{1}$, Xu Wang ${ }^{1}$, Jie Zhang ${ }^{1}$, Tianhui An ${ }^{1}$, Zhiying Ding ${ }^{2}$, Wanjing $\mathrm{Yu}^{1}$ and \\ Hui Tong ${ }^{1 *}$ \\ ${ }^{1}$ School of Metallurgy and Environment, Central South University, Changsha, China, ${ }^{2}$ School of Chemistry and Chemical \\ Engineering, Central South University, Changsha, China
}

Tin-based anode materials with high capacity attract wide attention of researchers and become a strong competitor for the next generation of lithium-ion battery anode materials. However, the poor electrical conductivity and severe volume expansion retard the commercialization of tin-based anode materials. Here, $\mathrm{SnO}_{2}-\mathrm{SnS}_{2} @ \mathrm{C}$ nanoparticles with heterostructure embedded in a carbon matrix of nitrogen-doped graphene $\left(\mathrm{SnO}_{2}-\mathrm{SnS}_{2} @ \mathrm{C} / \mathrm{NG}\right)$ is ingeniously designed in this work. The composite was synthesized by a two-step method. Firstly, the $\mathrm{SnO}_{2} @ \mathrm{C} / \mathrm{rGO}$ with a nanolayer structure was synthesized by hydrothermal method as the precursor, and then the $\mathrm{SnO}_{2}-\mathrm{SnS}_{2} @ \mathrm{C} / \mathrm{NG}$ composite was obtained by further vulcanizing the above precursor. It should be noted that a carbon matrix with nitrogen-doped graphene can inhibit the volume expansion of $\mathrm{SnO}_{2}-\mathrm{SnS}_{2}$ nanoparticles and promote the transport of lithium ions during continuous cycling. Benefiting from the synergistic effect between nanoparticles and carbon matrix with nitrogen-doped graphene, the heterostructured $\mathrm{SnO}_{2}-\mathrm{SnS}_{2} @ \mathrm{C} / \mathrm{NG}$ further fundamentally confer improved structural stability and reaction kinetics for lithium storage. As expected, the $\mathrm{SnO}_{2}-\mathrm{SnS}_{2} @ \mathrm{C} / \mathrm{NG}$ composite exhibited high reversible capacity $\left(1201.2 \mathrm{~mA} \mathrm{~h} \mathrm{~g}^{-1}\right.$ at the current rate of $\left.0.1 \mathrm{~A} \mathrm{~g}^{-1}\right)$, superior rate capability and exceptional long-life stability $\left(944.3 \mathrm{mAh} \mathrm{g}^{-1}\right.$ after 950 cycles at the current rate of $1.0 \mathrm{~A} \mathrm{~g}^{-1}$ ). The results demonstrate that the $\mathrm{SnO}_{2}-\mathrm{SnS}_{2} @ \mathrm{C} / \mathrm{NG}$ composite is a highly competitive anode material for LIBs.

Keywords: $\mathrm{SnO}_{2}-\mathrm{SnS}_{2}$, heterostructure, nitrogen-doped graphene, nanoparticle, anode

\section{INTRODUCTION}

In recent years, with the widespread use of portable electronic products and electric vehicles, lithium-ion battery technology needs to be rapidly upgraded (Armand and Tarascon, 2008; Wang et al., 2017a,b, 2019; Chen J. et al., 2018; Zheng et al., 2018; Tong et al., 2019). At present, the main problems faced by lithium-ion batteries (LIBs) are as follows: energy density, cycle life, safety and cost. These problems are mainly related to the anode and cathode of the battery. As far as anode materials are concerned, commercial graphite on the market today is unable to meet the increasing energy density requirements due to its lower capacity (about $372 \mathrm{mAh} \mathrm{g}^{-1}$ ) (Chen et al., 2018b; Xiao et al., 2018). In the past few decades, researchers developed many high-capacity and structurally 
stable anode materials, among which tin oxide anode materials with low discharge potential and natural abundance, received extensive attention and become a strong competitor for the next generation of lithium-ion battery anode materials (Chou et al., 2009; Sahoo and Ramaprabhu, 2018; Woo et al., 2018; Ye et al., 2019). Besides, owing to the conversion reaction $\left(\mathrm{SnO}_{2}+4 \mathrm{Li}^{+}\right.$ $\left.+4 \mathrm{e}^{-} \rightarrow \mathrm{Sn}+2 \mathrm{Li}_{2} \mathrm{O}\right)$ and alloying reaction $\left(\mathrm{Sn}+4.4 \mathrm{Li}^{+}\right.$ $\left.+4.4 \mathrm{e}^{-} \leftrightarrow \mathrm{Li}_{4.4} \mathrm{Sn}\right), \mathrm{SnO}_{2}$ anodes possess a high theoretical capacity (1,494 $\mathrm{mAh}^{-1}$ ) for lithium storage (Hu et al., 2017; Shao et al., 2017; Wang et al., 2018).

However, two main problems that delay the commercialization process of $\mathrm{SnO}_{2}$ anodes are poor conductivity and severe volume expansion. Researchers have done a lot of research work to solve these problems, and the most effective strategy at present is to combine with carbon materials (Du et al., 2014; Chen et al., 2018d; Hou et al., 2018; Li et al., 2018), which is indeed a great strategy. The introduction of carbon can limit the size of the material to obtain nanomaterials (Wang et al., 2013; Chen et al., 2018c). Nanoparticles can effectively reduce the absolute volume change of each particle, greatly improving the structural stability of the material. Furthermore, the charge-diffusion path of ions and electrons are greatly shortened and a large number of electrochemically active sites existed in nanoparticles (Ying and Han, 2017). On the other hand, the introduction of carbon can greatly improve the electrical conductivity of the material and enhance the structural stability of the material. Compared with other carbon materials, graphene has a two-dimensional layer structure with a single atomic thickness, remarkable structural flexibility, excellent electrical conductivity, high mechanical strength, and a large specific surface area. Therefore, graphene has obvious advantages in the application of electrode materials, and is an ideal substrate for dispersing and limiting active substances (Chen et al., 2018a; Li et al., 2019).

Recently, some researchers propose that the charge transfer kinetics can be enhanced by constructing a reasonable heterogeneous structure with built-in driving force (Jiang et al., 2017; Li et al., 2018; Ren et al., 2018). The synergistic effect of ion/electron transport originating from solidsolid heterojunctions is particularly important for electrode performance of essentially enhanced kinetics. In this context, superior electrochemical performance was demonstrated for $\mathrm{SnS} / \mathrm{SnO}_{2}$ (Li et al., 2018), $\mathrm{MoS}_{2} / \mathrm{SnS}_{2}$ (Jiang et al., 2017), $\mathrm{MnMoO}_{4} / \mathrm{CoMoO}_{4}$ (Chen H. et al., 2014), and $\mathrm{Fe}_{2} \mathrm{O}_{3} / \mathrm{Mn}_{2} \mathrm{O}_{3}$ (Ren et al., 2018). $\mathrm{SnS}_{2}$ is a CdI2 type layered structure material with a large interlayer spacing $(0.5899 \mathrm{~nm})$ and a narrow band gap (Xu et al., 2015). Moreover, since the bond energy of Sn-S is weaker than the bond energy of $\mathrm{Sn}-\mathrm{O}$, this will promote the conversion of $\mathrm{SnS}_{2}$ to Sn (Zhang S. et al., 2017; Wu et al., 2019). Therefore, the conversion reaction kinetics can be greatly improved by constructing a heterostructure between $\mathrm{SnO}_{2}$ and $\mathrm{SnS}_{2}$. Whereas, the development of synergistic ultra-fine heterogeneous interface lithium storage materials still faces enormous challenges.

Herein, we propose a facile and scalable fabrication approach of heterostructured $\mathrm{SnO}_{2}-\mathrm{SnS}_{2} @$ carbon/nitrogen-doped reduced graphene oxide $\left(\mathrm{SnO}_{2}-\mathrm{SnS}_{2} @ \mathrm{C} / \mathrm{NG}\right)$ composite.
In this hierarchical structure, the as-prepared $\mathrm{SnO}_{2}-\mathrm{SnS}_{2}$ nanoparticles were intimately embedded in carbon matrix with nitrogen-doped graphene, constructing an intimate cross-link conductive framework. Apart from the heterojunction structure of $\mathrm{SnO}_{2}-\mathrm{SnS}_{2}$, the carbon matrix with nitrogen-doped graphene accommodates the volume variation and facilitates the transport of lithium ions during continuous lithation/delithation cycling. The $\mathrm{SnO}_{2}-\mathrm{SnS}_{2} @ \mathrm{C} / \mathrm{NG}$ composite with hierarchical structure can fundamentally possess enhanced kinetics and reaction reversibility, thereby ensuring the stable cycling life.

\section{EXPERIMENTAL SECTION}

\section{Preparation of $\mathrm{SnO}_{2}-\mathrm{SnS}_{2} @ \mathrm{C} / \mathrm{NG}$ Composite}

All chemical reagents in this experiment are of analytical grade. The preparation method of $\mathrm{SnO}_{2} @ \mathrm{C} /$ reduced graphene oxide $\left(\mathrm{SnO}_{2} @ \mathrm{C} / \mathrm{rGO}\right)$ refers to our previous report (Li et al., 2019). Firstly, $30 \mathrm{~mL}$ of graphene oxide $(\mathrm{GO})$ solution $\left(0.5 \mathrm{mg} \mathrm{mL}^{-1}\right)$ was added to the beaker, and then $0.25 \mathrm{~g}$ of $\mathrm{SnCl}_{2}$ and $0.15 \mathrm{~g}$ of sodium alginate were thoroughly dispersed in the above GO solution, and slowly added to $30 \mathrm{~mL}$ of deionized water to form uniform solution. Secondly, the resulting solution was then hydrothermally treated at $180^{\circ} \mathrm{C}$ for $12 \mathrm{~h}$. After that, the obtained gray powder was calcined at $450^{\circ} \mathrm{C}$ for $1 \mathrm{~h}$ under $\mathrm{Ar}$ atmosphere to obtain $\mathrm{SnO}_{2} @ \mathrm{C} / \mathrm{rGO}$ composite. Finally, $0.2 \mathrm{~g}$ of the obtained precursor and $0.4 \mathrm{~g}$ of thioacetamide were added to $50 \mathrm{ml}$ of deionized water, and hydrothermally treated at $200^{\circ} \mathrm{C}$ for $15 \mathrm{~h}$ to obtain the desired $\mathrm{SnO}_{2}-\mathrm{SnS}_{2} @ \mathrm{C} / \mathrm{NG}$ composite. $\mathrm{SnO}_{2}$ $\mathrm{SnS}_{2} @ \mathrm{C}$ was prepared using the above method with $0.3 \mathrm{~g}$ of sodium alginate, and without using GO solution. $\mathrm{SnO}_{2} @ \mathrm{C}$ was prepared using the above method with $0.3 \mathrm{~g}$ of sodium alginate, and without using GO solution and no further vulcanization.

\section{Characterization}

The structure of $\mathrm{SnO}_{2}-\mathrm{SnS}_{2}$ composite was determined by X-ray diffraction (XRD, Bruker D8) with $\mathrm{Cu} \mathrm{K} \alpha$ radiation. The degree of the disorder of carbon was detected by Raman spectroscopy (HORIBA, Jobin-Yvon Lab RAM Aramis). The form of various elements in the $\mathrm{SnO}_{2}-\mathrm{SnS}_{2} @ \mathrm{C} / \mathrm{NG}$ was characterized by X-ray photoelectron spectroscopy (XPS, K-Alpha). The macroscopic morphology of the composite was observed by scanning electron microscopy (SEM, Zeiss Gemini DSM 982) and the microscopic morphology of the composite was observed by transmission electron microscopy (TEM, FEI Tecnai, G2 F20 STWIN). Thermogravimetric analyses (TGA, NETZSCH STA 409PG/PC) of the composites were performed in air with a heating rate of $5^{\circ} \mathrm{C}$ min $^{-1}$.

The electrochemical properties of the composites were evaluated using CR2025 cells. The composite material, conductive carbon (SP) and polyvinylidene fluoride (weight ratio $7: 2: 1$ ) were dispersed in $\mathrm{N}$-methylpyrrolidinone, and uniformly mixed to prepare a slurry. The slurry was uniformly coated on a copper foil current collector and dried at $120^{\circ} \mathrm{C}$ overnight, and the dried electrode sheets were controlled to have a loading density of $1.1-1.5 \mathrm{mg} \mathrm{cm}^{-2}$. The CR2025 batteries were assembled in a closed glove box, in which lithium tablets 
were used as the counter electrodes, and $1 \mathrm{M} \mathrm{LiPF}_{6}$ in ethylene carbonate and dimethyl carbonate (1:1, vol) was used as the electrolyte. The galvanostatic discharge/charging performances were tested by the battery test system (CT2001A, LAND) and the measured potential range was from 0.01 to $3.0 \mathrm{~V}$. Cyclic voltammetry curves $(\mathrm{CV}, 0.01-3.0 \mathrm{~V})$ and electrochemical impedance spectroscopy (EIS, $0.01-10^{5} \mathrm{~Hz}$ ) were recorded by electrochemical workstation measurements (CHI1000C, $\mathrm{CH}$ Instruments).

\section{RESULTS AND DISCUSSION}

The representative fabrication process of heterostructured $\mathrm{SnO}_{2}$ $\mathrm{SnS}_{2} @ \mathrm{C} / \mathrm{NG}$ is presented in Scheme 1. Firstly, the $\mathrm{SnO}_{2} @ \mathrm{C} / \mathrm{rGO}$ composite was synthesized by hydrothermal method, using sodium alginate and $\mathrm{GO}$ to produce carbon matrix $(\mathrm{C} / \mathrm{rGO})$. Then, $\mathrm{SnO}_{2}$ was partially vulcanized and grapheme was doped by nitrogen under hydrothermal reaction to finally obtain $\mathrm{SnO}_{2}$ $\mathrm{SnS}_{2} @ \mathrm{C} / \mathrm{NG}$ composite with a heterostructure structure, in which the thioacetamide works as a vulcanizing agent and a nitrogen dopant.

X-ray diffraction (XRD) patterns were collected to reveal the phase structures of the as-prepared $\mathrm{SnO}_{2}-\mathrm{SnS}_{2} @ \mathrm{C} / \mathrm{NG}$ and $\mathrm{SnO}_{2}-\mathrm{SnS}_{2} @ \mathrm{C}$ composites. As exhibited in Figure 1A, the sharp diffraction peaks for both samples were consistent with $\mathrm{SnO}_{2}$ (PDF No\#21-1250) and $\mathrm{SnS}_{2}$ (PDF\#22-0951), respectively. The strong diffraction peaks represent a high degree of crystallinity of the composite. The results indicate that the composites consisted of $\mathrm{SnO}_{2}$ and $\mathrm{SnS}_{2}$ mixtures. Additionally, no obvious peaks indexed into carbon were observed, suggesting the amorphous state of carbon and graphene. $\mathrm{SnO}_{2} @ \mathrm{C}$ sample (Figure S1A) was consistent with $\mathrm{SnO}_{2}$ (PDF No\#88-0287). To demonstrate the existence of graphene in composites, Raman spectroscopy at the range of $800-3.200 \mathrm{~cm}^{-1}$ were collected in Figure 1B. It shows two obvious peaks at 1,337 and $1,583 \mathrm{~cm}^{-1}$, assigning to the disorder of carbon materials for D-band and characteristic of $\mathrm{sp}^{2}$ hybridized carbon for G-band (Liu et al., 2010; Zhang et al., 2016). Compared with the $\mathrm{SnO}_{2}-\mathrm{SnS}_{2} @ \mathrm{C}$ and $\mathrm{SnO}_{2} @ \mathrm{C}$ (Figure S1B) $\left(\mathrm{I}_{\mathrm{D}} / \mathrm{I}_{\mathrm{G}}=0.72\right.$ and 0.71$)$, the $\mathrm{I}_{\mathrm{D}} / \mathrm{I}_{\mathrm{G}}$ ratio in $\mathrm{SnO}_{2}-\mathrm{SnS}_{2} @ \mathrm{C} / \mathrm{NG}$ (1.20) was much higher, suggesting that the existence of graphene, which is beneficial for the rapid electron transport. In addition, it can be found in the spectra that the $\mathrm{SnO}_{2}-\mathrm{SnS}_{2} @ \mathrm{C} / \mathrm{NG}$ composite had two distinct peaks at 2670.3 and $2916.1 \mathrm{~cm}^{-1}$ due to the $2 \mathrm{D}$ and $\mathrm{S} 3$ bands, respectively (Liu et al., 2010). Notably, the symmetric 2D band indicates the presence of a single layer of graphene in the $\mathrm{SnO}_{2}-\mathrm{SnS}_{2} @ \mathrm{C} / \mathrm{NG}$ composite (Shah et al., 2017). To determine the carbon and $\mathrm{SnS}_{2}$ content, TGA was estimated in air, as displayed in Figure 1C. As can be seen from the figure, the weight loss can be divided into three stages, which are divided into the following: the first stage is room temperature to $250^{\circ} \mathrm{C}$, the second stage is 250 to $450^{\circ} \mathrm{C}$, and the third stage is 450 to $600^{\circ} \mathrm{C}$. The weight loss in the first stage is due to the release of adsorbed water. The weight loss in the second stage corresponds to the conversion of $\mathrm{SnS}_{2}$ to $\mathrm{SnO}_{2}$ $\left(\mathrm{SnS}_{2}+3 \mathrm{O}_{2}=\mathrm{SnO}_{2}+\mathrm{SO}_{2} \uparrow\right)$ (Lu et al., 2018), meanwhile, $\mathrm{SnO}_{2}$ $\mathrm{SnS}_{2} @ \mathrm{C}$ and $\mathrm{SnO}_{2}-\mathrm{SnS}_{2} @ \mathrm{C} / \mathrm{NG}$ composites lost weights of 8.04 and $11.05 \mathrm{wt} \%$, respectively. It can be calculated that the contents of the $\mathrm{SnS}_{2}$ in $\mathrm{SnO}_{2}-\mathrm{SnS}_{2} @ \mathrm{C}$ and $\mathrm{SnO}_{2}-\mathrm{SnS}_{2} @ \mathrm{C} / \mathrm{NG}$ composites material are 45.75 and $62.88 \mathrm{wt} \%$, respectively, and the content of $\mathrm{SnO}_{2}$ produced from those are 37.71 and $51.83 \mathrm{wt} \%$, respectively. The weight loss in the third stage is ascribed to the oxidation of carbon, resulting in weight losses of 5.85 and $6.83 \mathrm{wt} \%$ for the $\mathrm{SnO}_{2}-\mathrm{SnS}_{2} @ \mathrm{C}$ and $\mathrm{SnO}_{2}-\mathrm{SnS}_{2} @ \mathrm{C} / \mathrm{NG}$ composites, respectively. Until the last stage, the remaining products were all $\mathrm{SnO}_{2}$, and the $\mathrm{SnO}_{2}-\mathrm{SnS}_{2} @ \mathrm{C}$ and $\mathrm{SnO}_{2}-\mathrm{SnS}_{2} @ \mathrm{C} / \mathrm{NG}$ composites retain 82.98 and $79.39 \mathrm{wt} \%$ (This contains two parts of $\mathrm{SnO}_{2}$ : one part is the original $\mathrm{SnO}_{2}$ in the composites and the other part is the $\mathrm{SnO}_{2}$ converted from $\mathrm{SnS}_{2}$ ), respectively. Furthermore, it is inferred the specific composition of each component in the composite, as listed in Table 1. Surface chemical elements of $\mathrm{SnO}_{2}-\mathrm{SnS}_{2} @ \mathrm{C}$ and $\mathrm{SnO}_{2}-\mathrm{SnS}_{2} @ \mathrm{C} / \mathrm{NG}$ composites were characterized by XPS analyses (Figure 1D). The S, O, Sn, and C elements were found in both composites in the full spectrum of XPS. Compared with $\mathrm{SnO}_{2}-\mathrm{SnS}_{2} @ \mathrm{C}$, it can be observed that $\mathrm{SnO}_{2}-\mathrm{SnS}_{2} @ \mathrm{C} / \mathrm{NG}$ had a

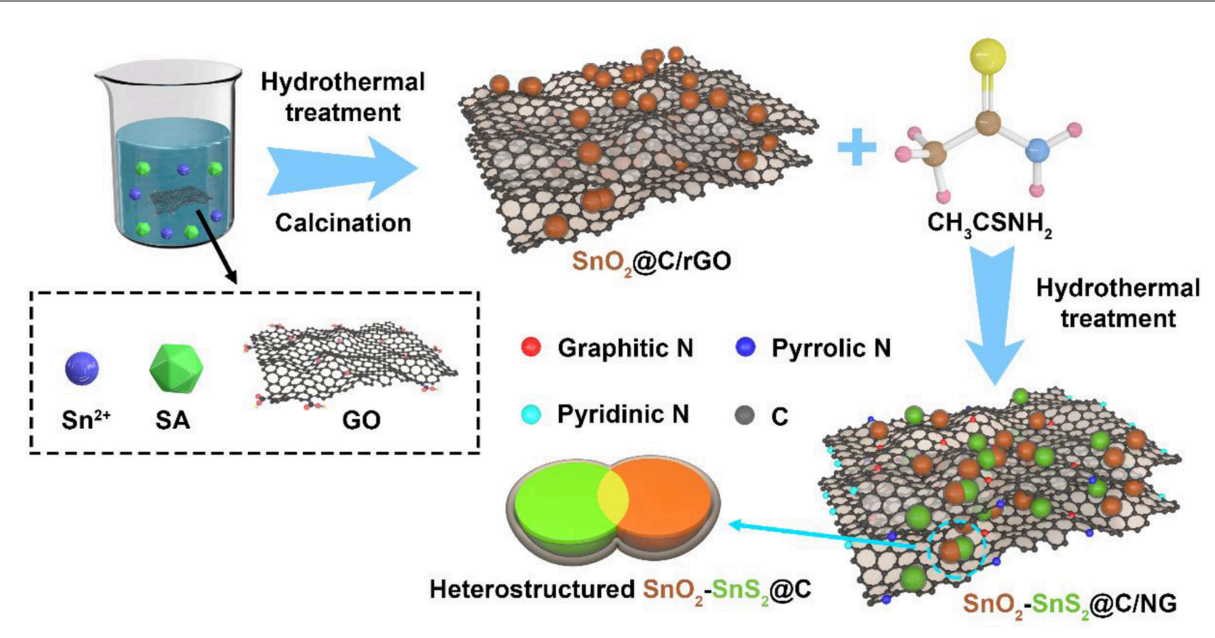

SCHEME 1 | Schematic illustration of the preparation process of $\mathrm{SnO}_{2}-\mathrm{SnS}_{2} @ \mathrm{C} / \mathrm{NG}$ composite. 

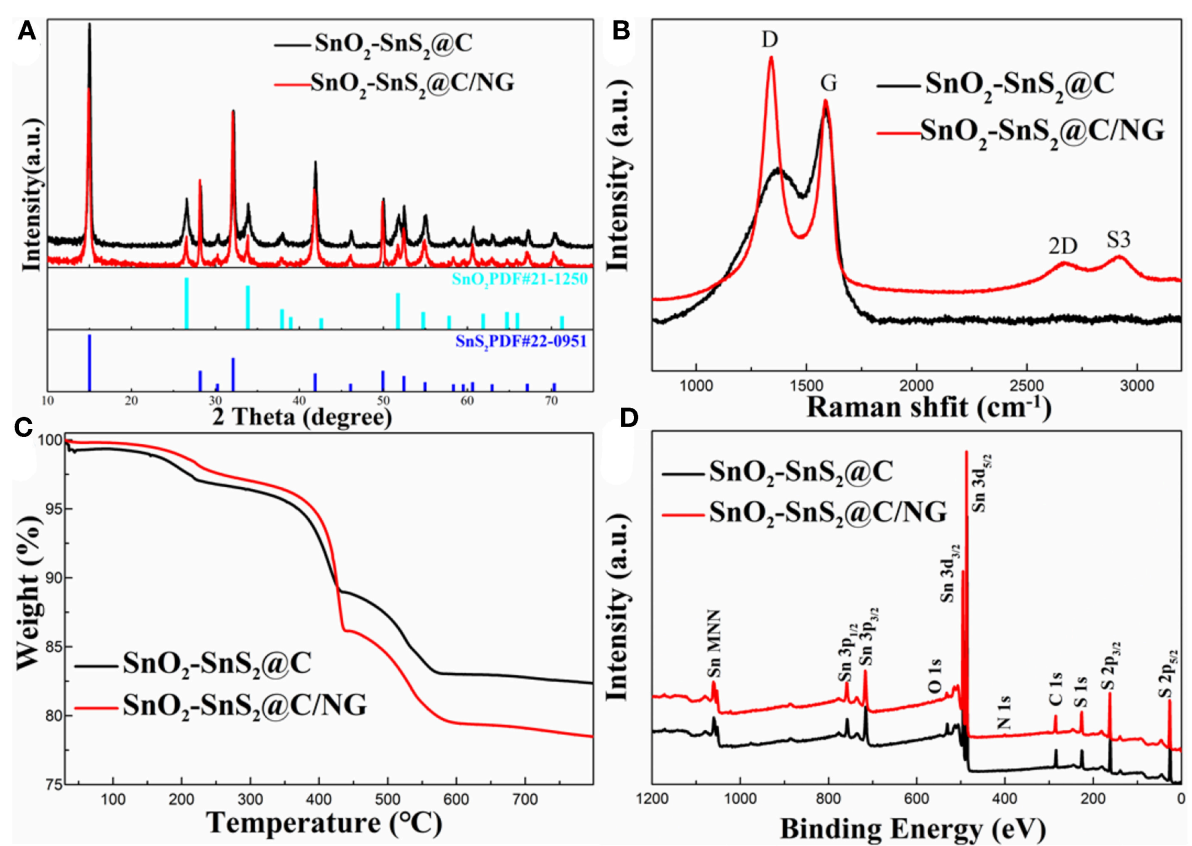

FIGURE 1 | (A) XRD patterns, (B) Raman spectra, (C) TGA curves, and (D) XPS spectra of $\mathrm{SnO}_{2}-\mathrm{SnS}_{2} @ \mathrm{C}$ and $\mathrm{SnO}_{2}-\mathrm{SnS}_{2} @ \mathrm{C} / \mathrm{NG}$ composites.

TABLE 1 | Contents of each component in the composites.

\begin{tabular}{|c|c|c|c|}
\hline & $\mathrm{SnO}_{2}(\mathrm{wt} \%)$ & $\mathrm{SnS}_{2}(\mathrm{wt} \%)$ & Carbon (wt\%) \\
\hline $\mathrm{SnO}_{2} @ \mathrm{C}$ (Figure S1C) & 90.56 & 0 & 5.80 \\
\hline $\mathrm{SnO}_{2}-\mathrm{SnS}_{2} @ \mathrm{C}$ & 45.27 & 45.75 & 5.85 \\
\hline $\mathrm{SnO}_{2}-\mathrm{SnS}_{2} @ \mathrm{C} / \mathrm{NG}$ & 62.88 & 27.56 & 6.83 \\
\hline
\end{tabular}

weak intensity peak of $\mathrm{N} 1 \mathrm{~s}$ at $400 \mathrm{~cm}^{-1}$, suggesting that the $\mathrm{N}$ element has been doped into the graphene lattice.

To obtain more information about the chemical state of the elements in the prepared $\mathrm{SnO}_{2}-\mathrm{SnS}_{2} @ \mathrm{C} / \mathrm{NG}$ composite, Highresolution XPS spectra are depicted in Figure 2. As shown in Figure 2A, the high-resolution Sn 3d XPS spectrum of the $\mathrm{SnO}_{2}-\mathrm{SnS}_{2} @ \mathrm{C} / \mathrm{NG}$ composite can be fitted to the intensity peaks at 487.2 and $495.6 \mathrm{eV}$, respectively, confirmed that tin in the composite exists in the form of $\mathrm{Sn}^{4+}$ (Lu et al., 2018). The $\mathrm{C} 1 \mathrm{~s}$ spectrum is applied to further analyze the carbon form in the $\mathrm{SnO}_{2}-\mathrm{SnS}_{2} @ \mathrm{C} / \mathrm{NG}$ composite. As observed in Figure 2B, the high-resolution $\mathrm{C}$ 1s XPS spectrum of $\mathrm{SnO}_{2}$ $\mathrm{SnS}_{2} @ \mathrm{C} / \mathrm{NG}$ can be fitted to three peaks located at 284.7, 285.5, and $286.9 \mathrm{eV}$ for $\mathrm{C}=\mathrm{C}, \mathrm{C}-\mathrm{N}$, and $\mathrm{C}-\mathrm{O}$, respectively ( $\mathrm{Li}$ et al., 2018). The relative weak intensity of the $\mathrm{C}-\mathrm{O}$ peak indicates that the oxide in the graphene is partially reduced. Besides, the presence of $\mathrm{C}-\mathrm{N}$ peak further demonstrates nitrogen doping into the graphene lattice, which opens the band gap, adjusts the conductivity type, changes the electronic structure, and increases the free carrier density in the graphene, thereby improving the conductivity of $\mathrm{SnO}_{2}-\mathrm{SnS}_{2} @ \mathrm{C} / \mathrm{NG}$ electrodes. By fitting the high-resolution $\mathrm{N} 1 \mathrm{~s}$ spectrum (Figure 2C), it can be found that $\mathrm{N}$ 1s spectrum can be divided into three peaks located in at 400.0, 401.8, and $402.7 \mathrm{eV}$, corresponding to the pyridinic, pyrrolic, and graphitic nitrogen atoms, respectively (Wu et al., 2018). Figure 2D shows the O 1s spectrum of the $\mathrm{SnO}_{2}-\mathrm{SnS}_{2} @ \mathrm{C} / \mathrm{NG}$ composite, which can be fitted into four types of oxygen-containing bond units located at 530.9, 531.2, 532.5 , and $534.9 \mathrm{eV}$, respectively. The peaks at 530.9, 531.2 and $532.5 \mathrm{eV}$ correspond to $\mathrm{O}-\mathrm{Sn}^{4+}, \mathrm{H}-\mathrm{O}-\mathrm{H}$, and $\mathrm{C}-\mathrm{O}-\mathrm{C}$ bonds, respectively. Notably, the peak at $534.9 \mathrm{eV}$ corresponds to the $\mathrm{S}-\mathrm{Sn}^{4+}-\mathrm{O}$ bond, which is a strong evidence of the presence of a heterojunction in the composite (Zhang et al., 2018). This confirmed the presence of a chemical bond between $\mathrm{SnO}_{2}$ and $\mathrm{SnS}_{2}$ particles.

The morphology and detailed structural feature of the prepared composite were observed by SEM, TEM and HRTEM. As can be observed in Figure 3a, the morphology of the $\mathrm{SnO}_{2}$ $\mathrm{SnS}_{2} @ \mathrm{C} / \mathrm{NG}$ composite shows an orderly lamination structure, forming a fluffy gap between the layers, which is very beneficial to the infiltration of the electrolyte. The ultrafine $\mathrm{SnO}_{2}-\mathrm{SnS}_{2}$ nanoparticles embedded into the crumpled carbon matrix, thereby forming tremendous voids in the composite. Due to the uniform distribution of nanosized particles, which are hardly observed from the SEM image (Figure 3b). In the absence of graphene-involved combination, the particles of the $\mathrm{SnO}_{2}$ $\mathrm{SnS}_{2} @ \mathrm{C}$ composite were agglomerated into microspheres of 200-300 $\mu \mathrm{m}$ diameter (Figure S2A). TEM is also applied to characterize the detailed structural feature of $\mathrm{SnO}_{2}-\mathrm{SnS}_{2} @ \mathrm{C} / \mathrm{NG}$ composite. As presented in Figure 3c, it can be clearly observed that the nanoparticles are perfectly wrapped by a single layer of graphene sheet. The graphene sheet in the figure also has void spaces and wrinkles, which can significantly suppress 

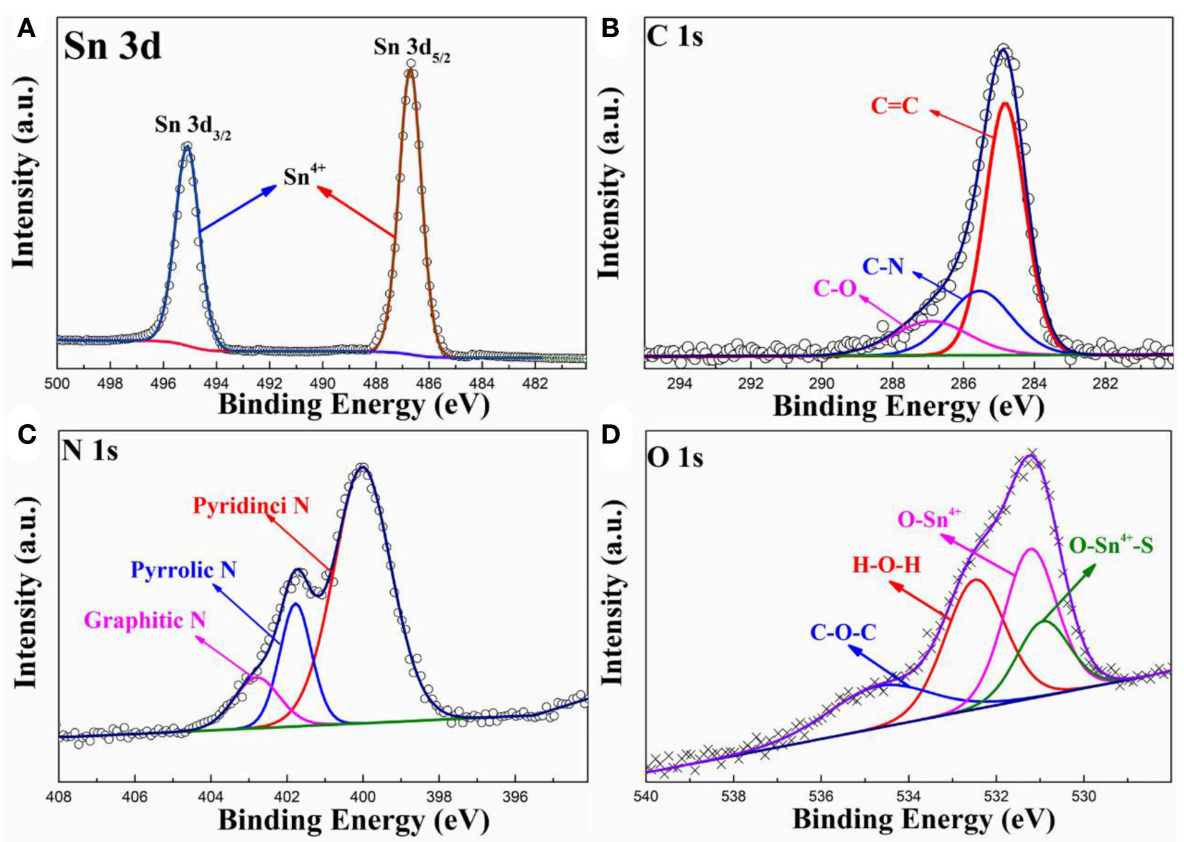

FIGURE 2 | High-resolution XPS spectra of (A) Sn 3d, (B) C 1s, (C) N 1s, and (D) O 1s spectra for SnO $2-S n S_{2} @ C / N G$ composite.

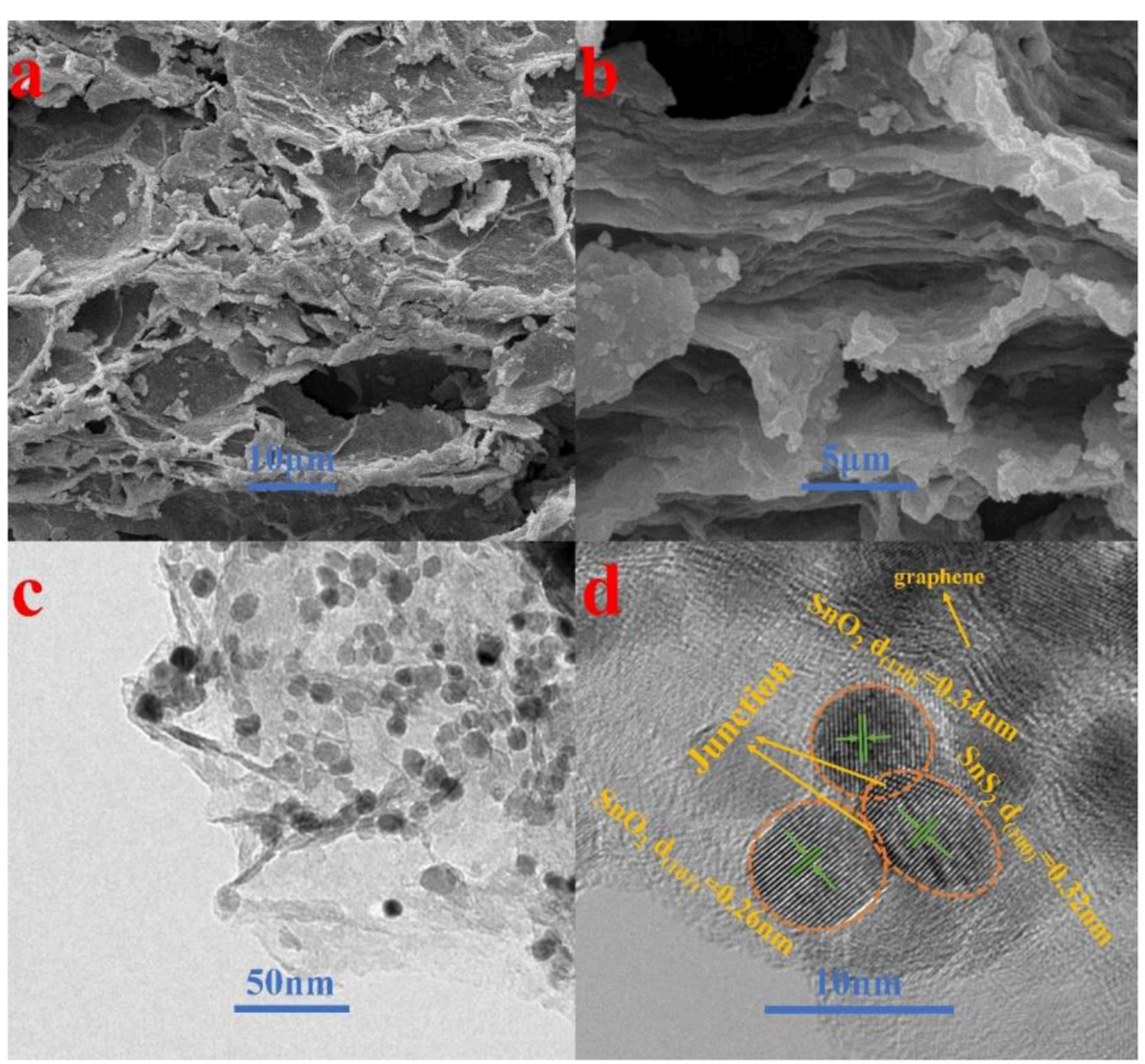

FIGURE 3 | (a,b) SEM, (c) TEM, and (d) HRTEM images of $\mathrm{SnO}_{2}-\mathrm{SnS}_{2} @ \mathrm{C} / \mathrm{NG}$ composite. 
the volume expansion of the nanoparticles and enhance the conductivity of the composites. Under the observation of TEM, it is found that the microspheres of $\mathrm{SnO}_{2}-\mathrm{SnS}_{2} @ \mathrm{C}$ composite (Figure S2B) are composed of primary particles of about $100-500 \mathrm{~nm}$, and the surface of the primary particles is covered with an amorphous carbon. Figure 3d clearly depicts the nanoparticles with the diameter of $5-10 \mathrm{~nm}$ and high degree of crystallization, which are uniformly embedded in graphene with a curved lattice fringe of $0.424 \mathrm{~nm}$. The particle in nanometer size can significantly shorten the lithium diffusion path and greatly improve the rate performance of the composite. Meanwhile, Figure 3d also displays the obvious several small nanocrystals with lattice spacings of $0.26,0.34$ and $0.32 \mathrm{~nm}$, corresponding to (101) and (110) planes of $\mathrm{SnO}_{2}$ and (100) plane of $\mathrm{SnS}_{2}$, respectively (Shi and $\mathrm{Lu}, 2014$; Chen et al., 2015; Shan et al., 2015; Yin et al., 2017). More importantly, as denoted in Figure 3d, the heterojunctions are formed in the overlapped junction regions. In Figure S2C, the heterojunction phenomenon of $\mathrm{SnO}_{2}-\mathrm{SnS}_{2} @ \mathrm{C}$ can also be found. The formation of heterojunctions composed of (101) plane of $\mathrm{SnO}_{2}$, (100) plane of $\mathrm{SnS}_{2}$, and (110) plane of $\mathrm{SnO}_{2}$, which strongly confirms the existence of heterogeneous $\mathrm{SnO}_{2}-\mathrm{SnS}_{2}$. Such a hierarchical structure is imperative for circumventing the selfaggregation of Sn-based nanoparticles, as well as the Sn and/or $\mathrm{Li}_{\mathrm{X}} \mathrm{Sn}$ nanoparticles produced during cycling. Additionally, EDS mapping illustrates the homogeneous distribution of $\mathrm{C}, \mathrm{N}, \mathrm{O}$, $\mathrm{S}$, and $\mathrm{Sn}$ elements on the $\mathrm{SnO}_{2}-\mathrm{SnS}_{2} @ \mathrm{C} / \mathrm{NG}$ composite, as presented in Figure 4, which is consistent with the TEM analysis. The characterization of various physical and chemical means suggests that $\mathrm{SnO}_{2}-\mathrm{SnS}_{2} @ \mathrm{C} / \mathrm{NG}$ composite is a well-designed hierarchical structure, in which heterojunctions composed of $\mathrm{SnO}_{2}$ and $\mathrm{SnS}_{2}$ ultrafine nanoparticles are encapsulated in nitrogen-doped graphene sheets.

In order to explore the mechanism reaction of the composite during the charging and discharging process, the $\mathrm{CV}$ curve in the first three cycles of $\mathrm{SnO}_{2}-\mathrm{SnS}_{2} @ \mathrm{C} / \mathrm{NG}$ electrode was studied, as shown in Figure 5A. During the first scan of the cathodic process, the peaks at 1.87 and $1.70 \mathrm{~V}$ are attributed to the $\mathrm{Li}$ deintercalation in the $\mathrm{SnS}_{2}$ layer, and there was no phase decomposition in this process, so the corresponding peaks were not found in the subsequent cycle (Yin et al., 2017). Decomposition of $\mathrm{SnS}_{2}$ to metallic tin and $\mathrm{Li}_{2} \mathrm{~S}$ results in a peak at $1.29 \mathrm{~V}$. The conversion of $\mathrm{SnO}_{2}$ and $\mathrm{SnO}$ to $\mathrm{Sn}$ produced a cathode peak at around $0.92 \mathrm{~V}$ and formed a synchronous products of $\mathrm{Li}_{2} \mathrm{O}$ and SEI film (Chen et al., 2015). The strong cathode peak at $0.18 \mathrm{~V}$ is attributed to $\mathrm{Li}_{\mathrm{x}} \mathrm{Sn}$ produced by the alloying reaction of elemental tin and lithium ions, and peak at the same potential was also observed in subsequent cycles, indicating that the alloying reaction here is reversible. In the anodic scan process, the strong peak at $0.5 \mathrm{~V}$ is caused by the de-alloying of $\mathrm{Li}_{\mathrm{x}} \mathrm{Sn}$, corresponding to the $0.18 \mathrm{~V}$ peak in the cathodic scan. The peak at $1.86 \mathrm{~V}$ is attributed to the oxidation and sulfurization of $\mathrm{Sn}$ to $\mathrm{SnO}_{2}$ and $\mathrm{SnS}_{2}$, respectively. The peak at $2.35 \mathrm{~V}$ is related to partial decomposition of $\mathrm{Li}_{2} \mathrm{~S}$, which also produces the first small irreversible capacity (Lu et al., 2018). It is worth noting that due to phase decomposition and structural collapse, the cathodic peak of $1.29 \mathrm{~V}$ in the first cycle shifted to $1.36 \mathrm{~V}$ in the subsequent cycle (Lu et al., 2018). Meanwhile, Figure 5B shows the first three discharge/charge curves of the $\mathrm{SnO}_{2}-\mathrm{SnS}_{2} @ \mathrm{C} / \mathrm{NG}$ composite, with a voltage window of $0.01-3.0 \mathrm{~V}$ and a current rate of $0.1 \mathrm{~A} \mathrm{~g}^{-1}$, which is consistent with the $\mathrm{CV}$ results. The first discharge/charge capacity achieved 1727.2 and $1201.2 \mathrm{mAh}^{-1}$, respectively, with initial coulombic efficiency of $69.54 \%$. The excess capacity may come from the formation of SEI film on the surface of active materials, lithium-insertion reaction in acetylene black and interfacial storage, which is similar to the phenomena of other Sn-based anodes (Chen Y. et al., 2014; Fu et al., 2018; Li et al., 2019). The low initial coulombic efficiency is mainly due to the formation of SEI films, which is usually observed for the nanosized anode materials (Liu et al., 2014; Yang et al., 2018), whereas the coulombic efficiency approached 99.9\% in the following cycles. In contrast, the initial charge capacity for $\mathrm{SnO}_{2}-\mathrm{SnS}_{2} @ \mathrm{C}$ reached $812.4 \mathrm{mAh} \mathrm{g}^{-1}$ under the

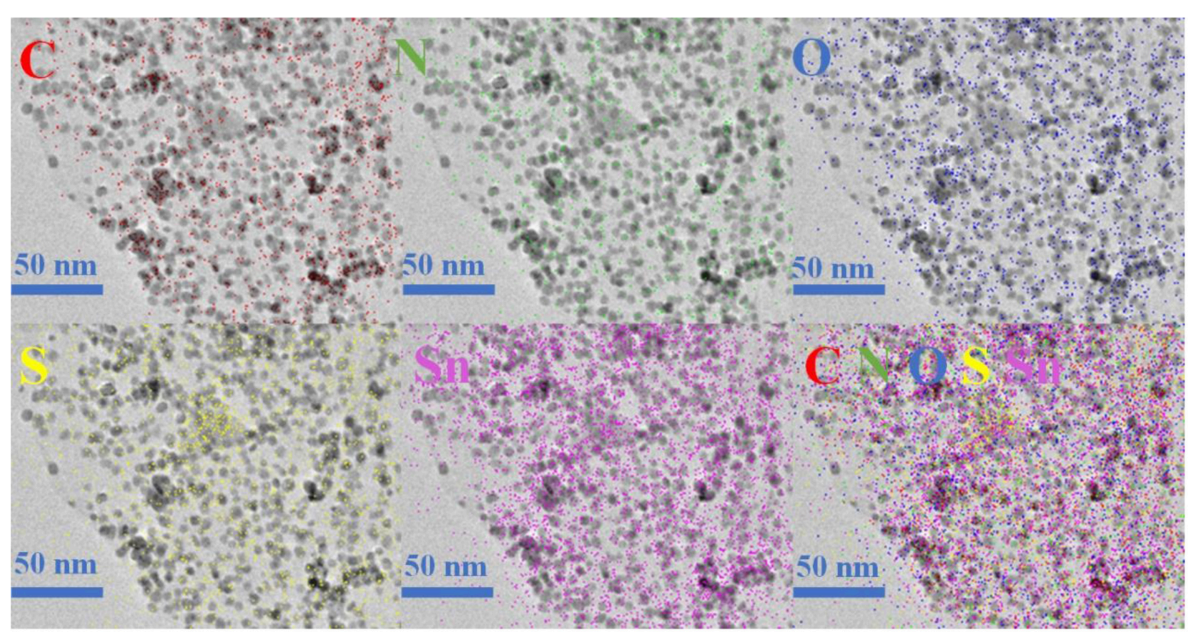

FIGURE 4 | EDS mapping images of $\mathrm{SnO}_{2}-\mathrm{SnS}_{2} @ \mathrm{C} / \mathrm{NG}$ composite. 

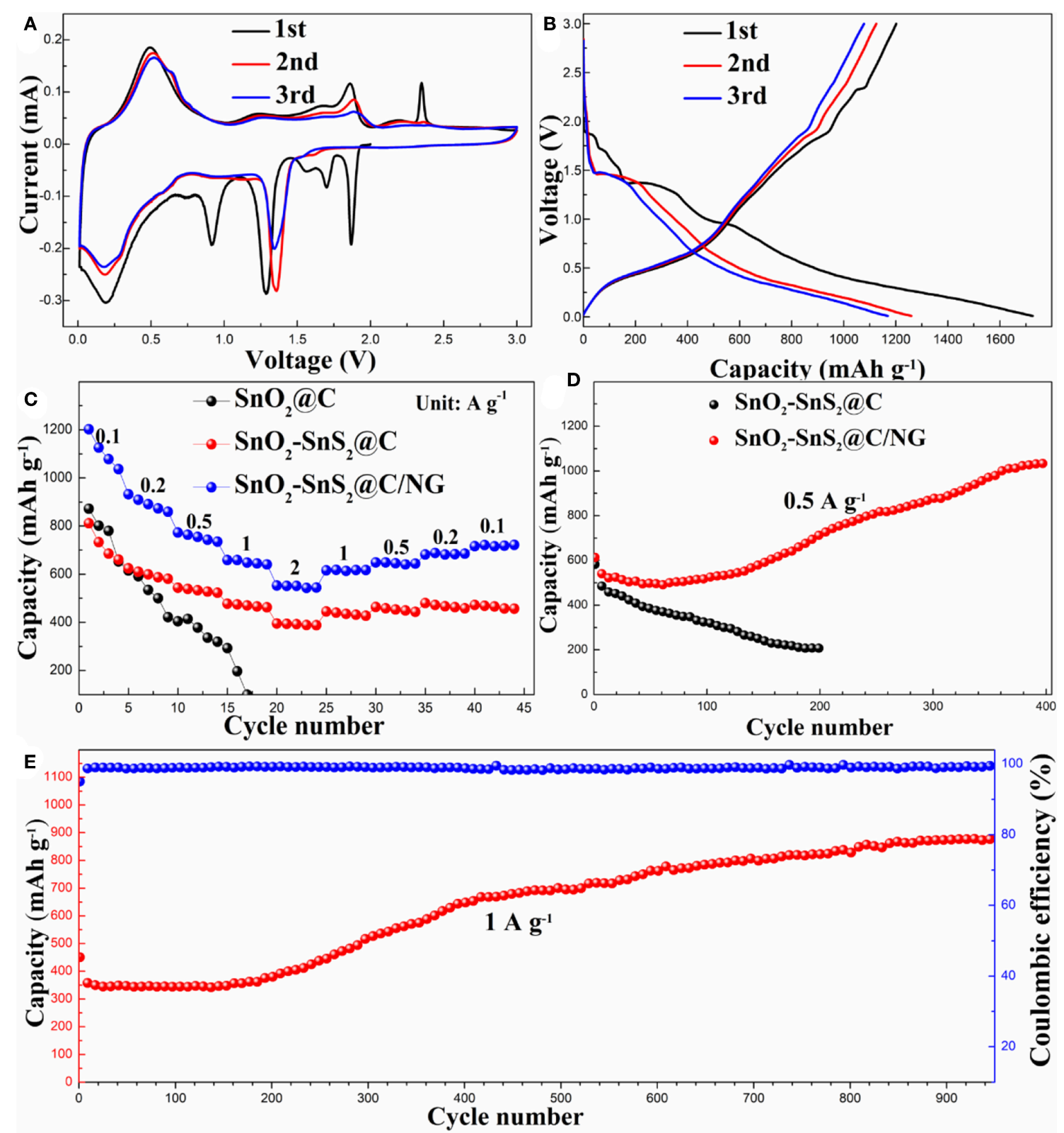

FIGURE 5 | (A) CV profiles and (B) the charge/discharge curves in the initial three cycles for $\mathrm{SnO}_{2}-\mathrm{SnS}_{2} @ \mathrm{C} / \mathrm{NG}$ composite. (C) Rate capabilities and (D) cycle

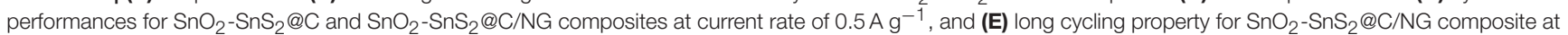
current rate of $1 \mathrm{~A} \mathrm{~g}^{-1}$.

same condition (Figure S3), which is relatively lower than that of $\mathrm{SnO}_{2}-\mathrm{SnS}_{2} @ \mathrm{C} / \mathrm{NG}$.

As depicted in Figure 5C, the rate capabilities of the composite electrodes were performed at various current rates ranging from 0.1 to $2 \mathrm{~A} \mathrm{~g}^{-1}$. The $\mathrm{SnO}_{2}-\mathrm{SnS}_{2} @ \mathrm{C}$ electrodes delivered stable capacities of 815.7, 628.6, 544.5, 478.6, and $395.8 \mathrm{mAh}$ $\mathrm{g}^{-1}$ at the rates of $0.1,0.2,0.5,1$, and $2 \mathrm{~A} \mathrm{~g}^{-1}$, respectively. When current rate returned to $0.1 \mathrm{~A} \mathrm{~g}^{-1}$, it recovered to $475.7 \mathrm{mAh}^{-1}$. In contrast, the rate performance of the $\mathrm{SnO}_{2} @ \mathrm{C}$ electrode was relatively poorer, as its capacity dropped sharply when the current density increased until the cell failed. The possible reason is that the heterojunction in the $\mathrm{SnO}_{2}$ $\mathrm{SnS}_{2} @ \mathrm{C}$ composite can significantly improve the conductivity, resulting in an increase in rate performance. Apparently, the rate performance of $\mathrm{SnO}_{2}-\mathrm{SnS}_{2} @ \mathrm{C} / \mathrm{NG}$ composite was the best. The $\mathrm{SnO}_{2}-\mathrm{SnS}_{2} @ \mathrm{C} / \mathrm{NG}$ electrodes delivered stable capacities of $1206.7,936.3,777.3,666.3$, and $559.0 \mathrm{mAh} \mathrm{g}^{-1}$ at the rates of $0.1,0.2,0.5,1$, and $2 \mathrm{~A} \mathrm{~g}^{-1}$, respectively. When the current rate returns to $0.1 \mathrm{~A} \mathrm{~g}^{-1}$, it still can recover to $724.1 \mathrm{mAh}$ $\mathrm{g}^{-1}$. The $\mathrm{SnO}_{2}-\mathrm{SnS}_{2} @ \mathrm{C} / \mathrm{NG}$ composite also exhibited the best 
cycle performance. The capacity of $\mathrm{SnO}_{2}-\mathrm{SnS}_{2} @ \mathrm{C} / \mathrm{NG}$ composite electrode at current rate of $0.5 \mathrm{~A} \mathrm{~g}^{-1}$ reached $717.6 \mathrm{mAh} \mathrm{g}^{-1}$ after 200 cycles and gradually increased to $1039.4 \mathrm{mAh} \mathrm{g}^{-1}$ after 400 cycles (Figure 5D). In addition, the charge and discharge curves for the 400th cycle of the $\mathrm{SnO}_{2}-\mathrm{SnS}_{2} @ \mathrm{C} / \mathrm{NG}$ composite are shown in the Figure $\mathbf{S} 4$. The capacity ratio in the voltage of $2.0-3.0 \mathrm{~V}$ was about $42 \%$, which may be related to the reversible formation of the polymer gel-like film. However, the $\mathrm{SnO}_{2}-\mathrm{SnS}_{2} @ \mathrm{C}$ electrode exhibited a low capacity of $208.0 \mathrm{~mA}$ h $\mathrm{g}^{-1}$ at $0.5 \mathrm{~A} \mathrm{~g}^{-1}$ after 200 cycles. Remarkably, at the high current rate of $1 \mathrm{~A} \mathrm{~g} \mathrm{~g}^{-1}$ (Figure 5E), the $\mathrm{SnO}_{2}-\mathrm{SnS}_{2} @ \mathrm{C} / \mathrm{NG}$ electrode still performed well after 950 cycles, exhibiting a strong reversible capacity of $944.3 \mathrm{mAh} \mathrm{g}^{-1}$, with the stabilized coulombic efficiency of around $99.5 \%$ throughout the whole cycling, confirming the merits of $\mathrm{SnO}_{2}-\mathrm{SnS}_{2} @ \mathrm{C} / \mathrm{NG}$ composite during the long-term cycling. In contrast with previous reported anodes materials, the $\mathrm{SnO}_{2}-\mathrm{SnS}_{2} @ \mathrm{C} / \mathrm{NG}$ composite exhibits outstanding cycle stability at higher current rates and
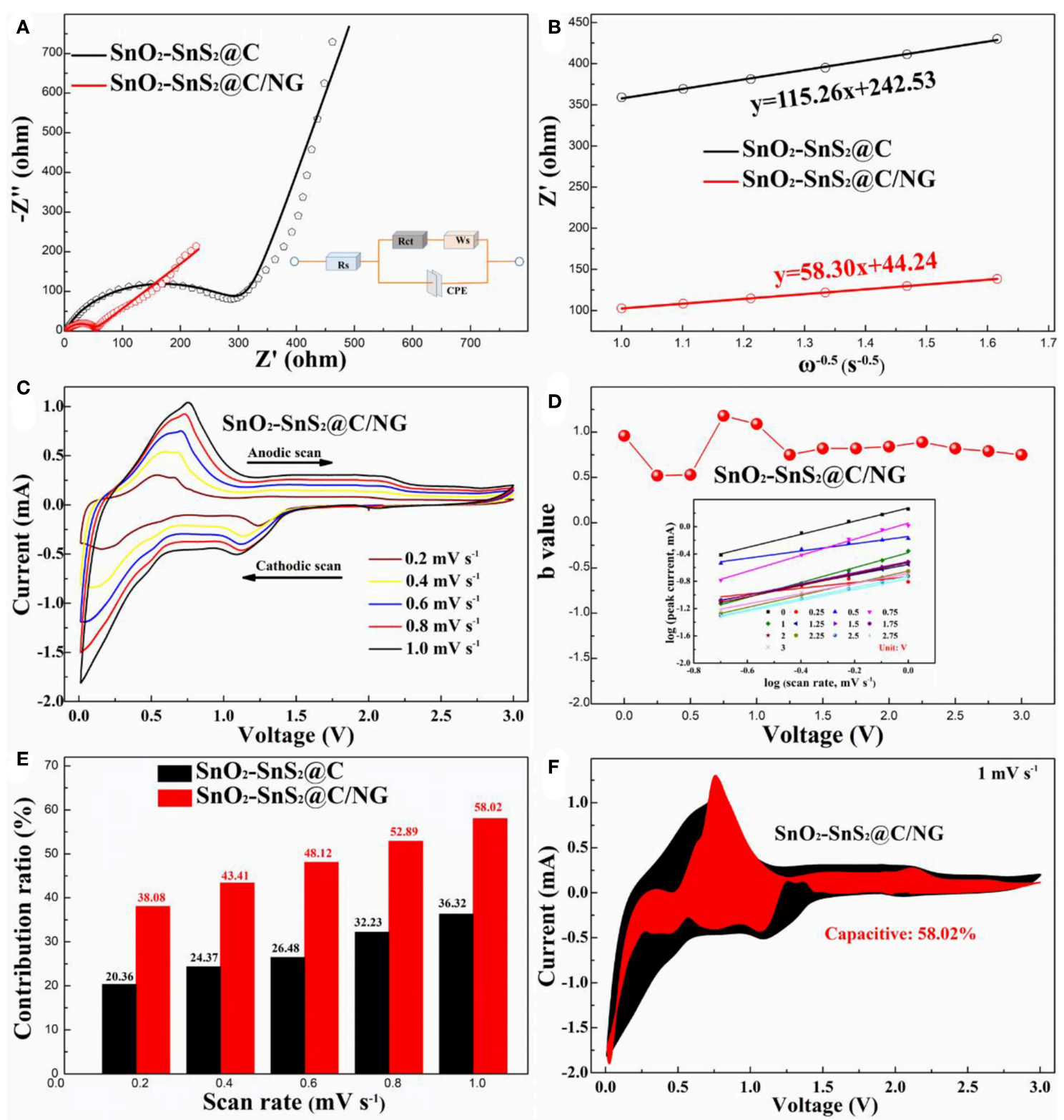

FIGURE 6 | (A) Nyquist plots and corresponding fitted curves of $\mathrm{SnO}_{2}-\mathrm{SnS}_{2} @ \mathrm{C}$ and $\mathrm{SnO}_{2}-\mathrm{SnS}_{2} @ \mathrm{C} / \mathrm{NG}$ electrodes before cycles (the inset is the modified equivalent circuit); (B) Nyquist plots and corresponding relationship between the real resistance (Z') and angular frequency $(\omega-0.5)$ for $\mathrm{SnO}_{2}-\mathrm{SnS} \mathrm{S}_{2} @ \mathrm{C}$ and $\mathrm{SnO} \mathrm{O}_{2}-\mathrm{SnS} \mathrm{S}_{2} @ \mathrm{C} / \mathrm{NG}$ electrodes; (C) CV curves of $\mathrm{SnO}_{2}-\mathrm{SnS}_{2} @ \mathrm{C} / \mathrm{NG}$ electrode at different scan rates from 0.2-1.0 $\mathrm{mV} \mathrm{s}^{-1}$; (D) b values plotted against cell voltage of SnO $\mathrm{b}_{2}-\mathrm{SnS}_{2} @ \mathrm{C} / \mathrm{NG}$ electrode for cathodic scans; (E) the percentage of the capacitance contribution for $\mathrm{SnO}_{2}-\mathrm{SnS}_{2} @ \mathrm{C}$ and $\mathrm{SnO} \mathrm{O}_{2}-\mathrm{SnS} \mathrm{S}_{2} @ \mathrm{C} / \mathrm{NG}$ at different scan rates; (F) CV curve of $\mathrm{SnO}_{2}-\mathrm{SnS}_{2} @ \mathrm{C} / \mathrm{NG}$ at a sweep rate of $1.0 \mathrm{mV} \mathrm{s}^{-1}$, and the estimated capacitive current contribution is shown in the shaded region. 
exhibits outstanding electrochemical performance (as shown in Table S1). It is noteworthy that the capacity had a slightly decrease during the first 50 cycles, then gradually increased during the subsequent cycles, and finally maintaining a stable performance. This phenomenon is attributed to the electrode activation and reversible formation of the polymer gel-like film, followed by the continuous reconstruction of SEI film on the surface of nanomaterials (Wang et al., 2013; Zhou et al., 2013; Liu et al., 2014).

In order to gain a deep understanding of the excellent electrochemical properties and to evaluate the lithium storage kinetics and charge transfer capacity of the composites, the $\mathrm{SnO}_{2}$ $\mathrm{SnS}_{2} @ \mathrm{C}$ and $\mathrm{SnO}_{2}-\mathrm{SnS}_{2} @ \mathrm{C} / \mathrm{NG}$ electrodes were investigated by EIS. As displayed in Figure 6A, all Nyquist plots consist of a depressed semicircle at high frequency and a straight drift at low-medium frequency, which can be perfect fitted with an equivalent circuit as displayed in the insert of Figure 6A. Compared with charge-transfer resistance $\left(\mathrm{R}_{\mathrm{ct}}\right)$ of $\mathrm{SnO}_{2}$ $\mathrm{SnS}_{2} @ \mathrm{C}(323.6 \Omega)$, the $\mathrm{R}_{\mathrm{ct}}$ of $\mathrm{SnO}_{2}-\mathrm{SnS}_{2} @ \mathrm{C} / \mathrm{NG}(47.37 \Omega)$ is much smaller. Furthermore, the lithium-ion diffusion coefficient $\left(\mathrm{D}_{\mathrm{Li}+}\right)$ can be further calculated according to the following equations (Yi et al., 2017; Zhang B. et al., 2017; Tong et al., 2018) (R, gas constant; $T$, absolute temperature; A, surface area; n, average reacted electrons; F, Faraday constant; C, $\mathrm{Li}^{+}$ concentration, respectively):

$$
\begin{array}{r}
\mathrm{D}_{\mathrm{Li}}^{+}=\mathrm{R}^{2} \mathrm{~T}^{2} / 2 \mathrm{~A}^{2} \mathrm{n}^{4} \mathrm{~F}^{4} \mathrm{C}^{2} \sigma^{2} \\
\mathrm{Z}^{\prime}=\mathrm{R}_{\mathrm{s}}+\mathrm{R}_{\mathrm{ct}}+\sigma \omega^{1 / 2}
\end{array}
$$

in which, $\sigma$ can be calculated by the plot of $Z^{\prime}$ vs. $\omega^{-0.5}$ (angular frequency) as depicted in Figure 6B. Therefore, the calculated values of $\mathrm{D}_{\mathrm{Li}}^{+}$listed in Table $\mathbf{S} 2$ imply the rapid diffusion of lithium ions and excellent reaction kinetics of the $\mathrm{SnO}_{2}-\mathrm{SnS}_{2} @ \mathrm{C} / \mathrm{NG}$ electrode.

In order to further explore the excellent rate performance of the $\mathrm{SnO}_{2}-\mathrm{SnS}_{2} @ \mathrm{C} / \mathrm{NG}$ electrode, $\mathrm{CV}$ analyses at various scan rates from 0.2 to $1 \mathrm{mV} \mathrm{s}^{-1}$ were carried out (Figure 6C). Considering that $\mathrm{SnO}_{2}-\mathrm{SnS}_{2} @ \mathrm{C} / \mathrm{NG}$ is superior than $\mathrm{SnO}_{2}$ $\mathrm{SnS}_{2} @ \mathrm{C}$ in high-rate performance and fast lithium ion transport, the pseudocapacitance contribution of $\mathrm{SnO}_{2}$ $\mathrm{SnS}_{2} @ \mathrm{C} / \mathrm{NG}$ may be more than that of $\mathrm{SnO}_{2}-\mathrm{SnS}_{2} @ \mathrm{C}$ during charge/discharge process. In this case, the ratios of capacitive contribution can be further quantitatively quantified by separating the current response (i) at a fixed potential $(\mathrm{V})$ into capacitive contribution $\left(k_{1} v\right)$ and
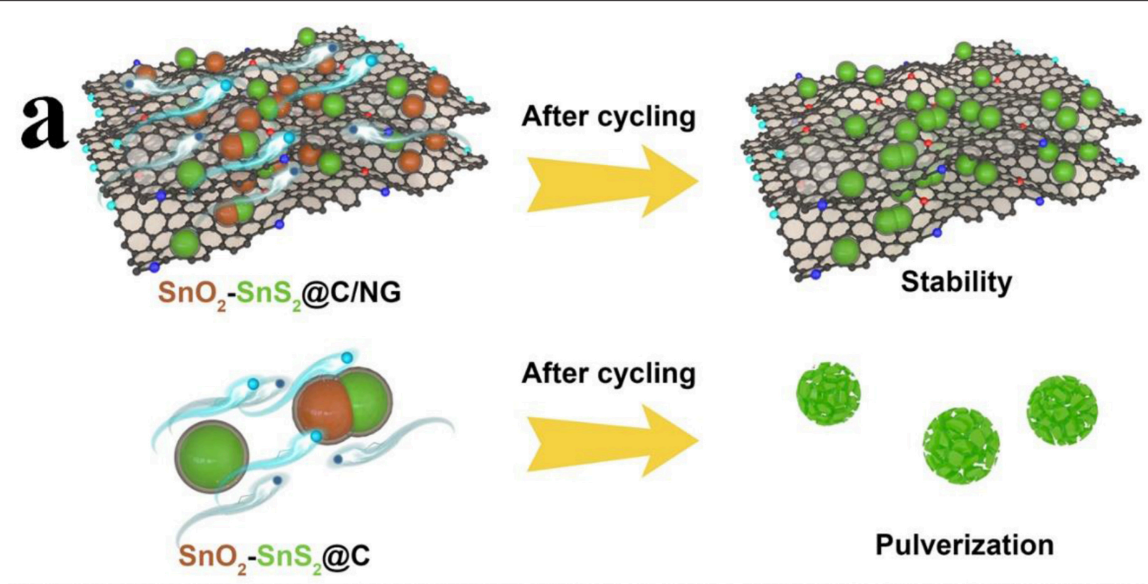

Pulverization

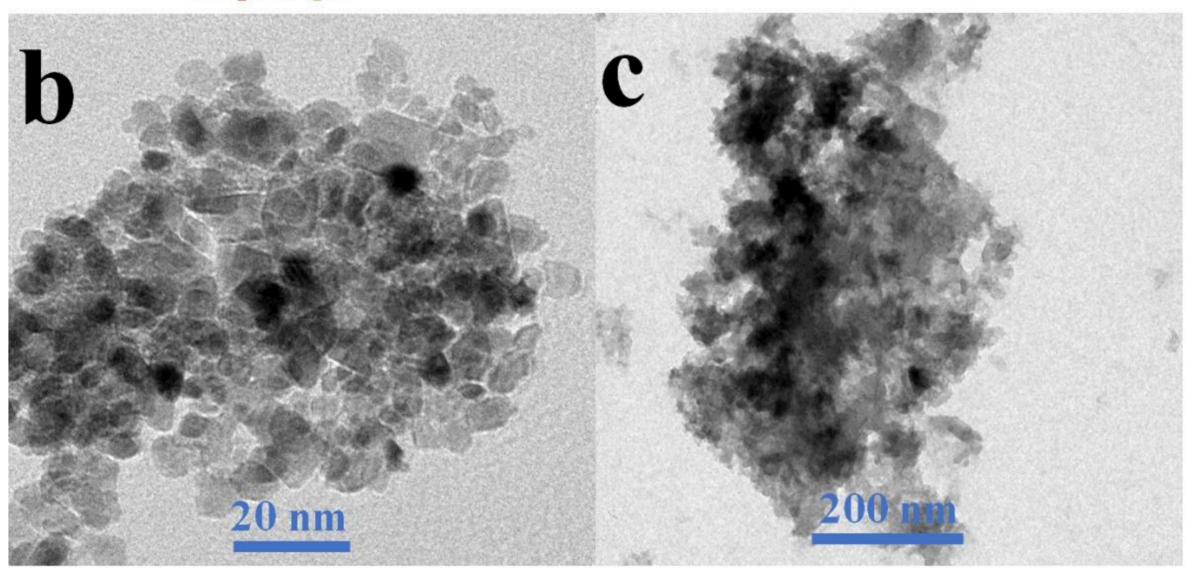

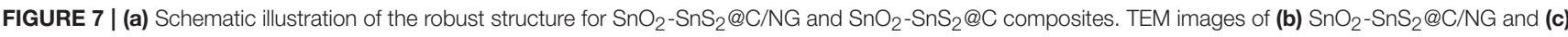
$\mathrm{SnO}_{2}-\mathrm{SnS}_{2} @ \mathrm{C}$ composites after cycling test. 
diffusion-controlled contribution $\left(k_{2} v^{1 / 2}\right)$, according to the following equation:

$$
i=k_{1} v+k_{2} v^{1 / 2}=a v^{b}
$$

in which, $a$ and $b$ present adjustable values. It must be noted that there is no proportional relationship between the measured current $(i)$ and the square root of the scan rate $(v)$ at a certain potential, suggesting the redox process can hardly be assigned to entire ion-diffusion control. The value of $b$ is usually between 0.5 and 1 , where 0.5 represents the diffusion control process and 1.0 illustrates the ideal pseudocapacitive behavior according to previous mechanism (Zhao et al., 2017). As displayed in Figure 6D, by fitting $\log (i)$ and $\log (v)$ at various redox potentials, several b values $>0.8$ can be obtained therefrom, demonstrating a dominated pseudocapacitive-controlled contribution process for the $\mathrm{SnO}_{2}$ $\mathrm{SnS}_{2} @ \mathrm{C} / \mathrm{NG}$ electrode. Furthermore, the contribution of total pseudocapacitive at a specific scan rate can be accurately calculated by the following equation ((Zhao et al., 2017); Zhang et al., 2018):

$$
i(V) / v^{1 / 2}=k_{1} v^{1 / 2}+k_{2}
$$

By carefully comparing the capacity contributions at different scan rates (Figure 6E), it is not difficult to conclude that the percentage of pseudocapacitive contribution increases gradually as the scan rate increases, and the lithiation/delithiation reaction of the $\mathrm{SnO}_{2}-\mathrm{SnS}_{2} @ \mathrm{C} / \mathrm{NG}$ composite gradually becomes capacitive control, and the pseudocapacitivecontrolled contribution ratios of the $\mathrm{SnO}_{2}-\mathrm{SnS}_{2} @ \mathrm{C} / \mathrm{NG}$ composite are always higher than those of the $\mathrm{SnO}_{2}-\mathrm{SnS}_{2} @ \mathrm{C}$ composite. As highlighted in Figure 6F, when the scan rate is $1 \mathrm{mV} \mathrm{s}^{-1}$, nearly $58.02 \%$ of the total current (red region) is attributed to the pseudocapacitive contribution for the $\mathrm{SnO}_{2}-\mathrm{SnS}_{2} @ \mathrm{C} / \mathrm{NG}$ electrode, which is the maximum at all scan rates.

The distinct pseudocapacitive behavior and enhanced reaction kinetic proved by EIS results are originated from the synergistic effect of $\mathrm{SnO}_{2}-\mathrm{SnS}_{2}$ heterojunction incorporated into the highly conductive $\mathrm{N}$-doped graphene. The ultrafine $\mathrm{SnO}_{2}$ $\mathrm{SnS}_{2}$ nanoparticles can provide shorten transport distance of lithium ions, especially the formation of heterojunctions at the interface of $\mathrm{SnO}_{2}-\mathrm{SnS}_{2}$ nanoparticles effectively enhance the electronic transmission, which greatly promote the rate capability. Furthermore, nitrogen-doped graphene also plays a key role in lithium ion and electronic conductivity, which can build highly-conductive framework among the dispersive nanoparticles with integrity architecture, efficiently facilitating the lithium transport path and thus resulting in the excellent electrochemical performance.

The nitrogen-doped graphene nanosheets interconnect the nanoparticles and act as cushions for its volume expansion during long-term lithiation/delithiation process, further enhancing the structural stability and improving the life-cycle of entire electrode, as schematically illustrated in Figure 7a. The correlations between cycling properties and structural features for the as-prepared $\mathrm{SnO}_{2}-\mathrm{SnS}_{2} @ \mathrm{C} / \mathrm{NG}$ and $\mathrm{SnO}_{2}$ $\mathrm{SnS}_{2} @ \mathrm{C}$ composites were characterized by TEM tests after 400th cycle at the current rate of $0.5 \mathrm{~A} \mathrm{~g}^{-1}$. As presented in Figure $7 \mathbf{b}$, the flake morphology of $\mathrm{SnO}_{2}-\mathrm{SnS}_{2} @ \mathrm{C} / \mathrm{NG}$ was well-maintained after long-term cycling. The repeated volume expansion is effectively restricted by the robust architecture of the carbon matrix, in which the amorphous carbon locks the $\mathrm{SnO}_{2}-\mathrm{SnS}_{2}$ nanoparticles on the nitrogen-doped graphene sheets, inhibiting its severe volume variation. In comparison, $\mathrm{SnO}_{2}-\mathrm{SnS}_{2} @ \mathrm{C}$ composite without incorporation of graphene suffer from the particle pulverization and agglomeration after continuous cycling (Figure 7c), and the nanoparticles are easily detached from the current collector, which leads to the unstable structure and severe electrode degradation with bad cycling performance. Furthermore, the repeated formation of thick SEI films overlying on the surface $\mathrm{SnO}_{2}-\mathrm{SnS}_{2}$ particles has adverse effects on the reversibility of conversion reaction, directly impeding the lithium ion and electron transfer and resulting in the continuous capacity decrease. All results indicate that heterostructured $\mathrm{SnO}_{2}-\mathrm{SnS}_{2} @ \mathrm{C} / \mathrm{NG}$ composite demonstrates enhanced structural stability and superior electrochemical performance.

\section{CONCLUSIONS}

In this work, the well-designed $\mathrm{SnO}_{2}-\mathrm{SnS}_{2} @ \mathrm{C} / \mathrm{NG}$ composite was ingeniously fabricated by a facile approach, in which the heterojunction of $\mathrm{SnO}_{2}-\mathrm{SnS}_{2}$ was created and embedded into the carbon matrix with highly conductive nitrogendoped graphene nanosheets. As expected, $\mathrm{SnO}_{2}-\mathrm{SnS}_{2} @ \mathrm{C} / \mathrm{NG}$ composite exhibited a high reversible capacity $(1201.2 \mathrm{~mA} \mathrm{~h}$ $\mathrm{g}^{-1}$ at current rate of $\left.0.1 \mathrm{~A} \mathrm{~g}^{-1}\right)$, superior rate capability

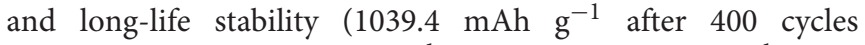
at current rate of $0.5 \mathrm{~A} \mathrm{~g}^{-1}$, and $944.3 \mathrm{mAh} \mathrm{g}^{-1}$ after 950 cycles at current rate of $1.0 \mathrm{~A} \mathrm{~g}^{-1}$ ). The excellent electrochemical properties may be ascribed to the following reasons. The lithium ion diffusion path is shortened in $\mathrm{SnO}_{2}-\mathrm{SnS}_{2}$ nanoparticles with ultrafine size, and reversibility and reaction kinetics are enhanced through the introduction of heterostructure. Meanwhile, the nitrogen-doped graphene sheets improve the electronic conductivity and structural stability, which can effectively accommodate the volume variation and maintain the steady formation of SEI films without particle pulverization. This strategy contributes a new insight for preparing the high-performance electrode materials for LIBs.

\section{DATA AVAILABILITY}

The raw data supporting the conclusions of this manuscript will be made available by the authors, without undue reservation, to any qualified researcher.

\section{AUTHOR CONTRIBUTIONS}

HL carried out the experiment and wrote the manuscript. XW, JZ, and TA participated in the experiment. $\mathrm{BZ}, \mathrm{ZD}$ and $\mathrm{WY}$ contributed to the 
discussion. HT supervised the experiment and proofread the manuscript.

\section{ACKNOWLEDGMENTS}

This work was supported by National Natural Science Foundation of China (Grant No. 51502350, 51772334, and 51702367), China Postdoctoral Science Foundation (Grant No. 2016M592447), The International Postdoctoral

\section{REFERENCES}

Armand, M., and Tarascon, J. M. (2008). Building better batteries. Nature 451, 652-657. doi: 10.1038/451652a

Chen, C.-Y., Yokoshima, T., Nara, H., Momma, T., and Osaka, T. (2015). One-step hydrothermal synthesis of $\mathrm{SnS}_{2} / \mathrm{SnO}_{2} / \mathrm{C}$ hierarchical heterostructures for li-ion batteries anode with superior rate capabilities. Electrochim. Acta 183, 78-84. doi: 10.1016/j.electacta.2015.05.079

Chen, H., Hu, L., Chen, M., Yan, Y., and Wu, L. (2014). Nickel-cobalt layered double hydroxide nanosheets for high-performance supercapacitor electrode materials. Adv. Funct. Mater. 24, 934-942. doi: 10.1002/adfm.201301747

Chen, H., Huang, Y., Mao, G., Tong, H., Yu, W., Zheng, J., et al. (2018a). Reduced graphene oxide decorated $\mathrm{Na}_{3} \mathrm{~V}_{2}\left(\mathrm{PO}_{4}\right)_{3}$ microspheres as cathode material with advanced sodium storage performance. Front. Chem. 6:174. doi: $10.3389 /$ fchem.2018.00174

Chen, H., Zhang, B., Cao, Y., Wang, X., Yao, Y., Yu, W., et al. (2018b). ZnS nanoparticles embedded in porous honeycomb-like carbon nanosheets as high performance anode material for lithium ion batteries. Ceramics Int. 44, 13706-13711. doi: 10.1016/j.ceramint.2018.04.211

Chen, H., Zhang, B., Wang, X., Dong, P., Tong, H., Zheng, J. C., et al. (2018c). CNT-decorated $\mathrm{Na}_{3} \mathrm{~V}_{2}\left(\mathrm{PO}_{4}\right)_{3}$ microspheres as a high-rate and cycle-stable cathode material for sodium ion batteries. ACS Appl. Mater. Interfaces 10, 3590-3595. doi: 10.1021/acsami.7b16402

Chen, H., Zhang, B., Zhang, J., Yu, W., Zheng, J., Ding, Z., et al. (2018d). In-situ grown $\mathrm{SnS}_{2}$ nanosheets on $\mathrm{rGO}$ as an advanced anode material for lithium and sodium ion batteries. Front. Chem. 6:629. doi: 10.3389/fchem.2018.00629

Chen, J., Li, L., Wu, L., Yao, Q., Yang, H., Liu, Z., et al. (2018). Enhanced cycle stability of $\mathrm{Na}_{0.9} \mathrm{Ni}_{0.45} \mathrm{Mn}_{0.55} \mathrm{O}_{2}$ through tailoring O3/P2 hybrid structures for sodium-ion batteries. J. Power Sources 406, 110-117. doi: 10.1016/j.jpowsour.2018.10.058

Chen, Y., Song, B., Chen, R. M., Lu, L., and Xue, J. (2014). A study of the superior electrochemical performance of $3 \mathrm{~nm} \mathrm{SnO}_{2}$ nanoparticles supported by graphene. J. Mater. Chem. A, 2, 5688-5695. doi: 10.1039/C3TA14745B

Chou, W.-Y., Yeh, B.-L., Cheng, H.-L., Sun, B.-Y., Cheng, Y. C., Lin, Y.S., et al. (2009). Organic complementary inverters with polyimide films as the surface modification of dielectrics. Organ. Electronics 10, 1001-1005. doi: 10.1016/j.orgel.2009.03.017

Du, F. H., Liu, Y. S., Long, J., Zhu, Q. C., Wang, K. X., Wei, X., et al. (2014). Incorporation of heterostructured $\mathrm{Sn} / \mathrm{SnO}$ nanoparticles in crumpled nitrogendoped graphene nanosheets for application as anodes in Lithium-ion batteries. Chem. Commun. 50, 9961-9964. doi: 10.1039/C4CC04187A

Fu, S., Wu, Q., He, S., Tong, S., Yang, X., Meng, Y., et al. (2018). Ultrafine $\mathrm{SnO}_{2}$ nanocrystals self-anchored in carbon for stable lithium storage. ChemElectroChem 5, 2341-2347. doi: 10.1002/celc.201800631

Hou, C. X., Tai, Z. X., Zhao, L. L., Zhai, Y. J., Hou, Y., Fan, Y. Q., et al. (2018). High performance $\mathrm{MnO} @ \mathrm{C}$ microcages with a hierarchical structure and tunable carbon shell for efficient and durable lithium storage. J. Mater. Chem. A 6, 9723-9736. doi: 10.1039/C8TA02863J

Hu, L. L., Yang, L. P., Zhang, D., Tao, X. S., Zeng, C., Cao, A. M., et al. (2017). Designed synthesis of $\mathrm{SnO}_{2}-\mathrm{C}$ hollow microspheres as an anode material for lithium-ion batteries. Chem. Commun. 53, 11189-11192. doi: 10.1039/C7CC05747D

Jiang, Y., Guo, Y., Lu, W., Feng, Z., Xi, B., Kai, S., et al. (2017). Rationally incorporated $\mathrm{MoS}_{2} / \mathrm{SnS}_{2}$ nanoparticles on graphene sheets for lithium-ion
Exchange Fellowship Program (Grant No. 155212), and Hunan Provincial Innovation Foundation for Postgraduate (CX2017B060).

\section{SUPPLEMENTARY MATERIAL}

The Supplementary Material for this article can be found online at: https://www.frontiersin.org/articles/10.3389/fchem. 2019.00339/full\#supplementary-material

and sodium-ion batteries. ACS Appl. Mater. Interfaces 9, 27697-27706. doi: 10.1021/acsami.7b06572

Li, H., Zhang, B., Zhou, Q., Zhang, J., Yu, W., Ding, Z., et al. (2019). Dual-carbon confined $\mathrm{SnO}_{2}$ as ultralong-life anode for Li-ion batteries. Ceramics Int. 45, 7830-7838. doi: 10.1016/j.ceramint.2019.01.090

Li, M., Deng, Q., Wang, J., Jiang, K., Shang, L., Hu, Z., et al. (2018). Insitu gas reduction in reversible $\mathrm{SnS}-\mathrm{SnO}_{2} @ \mathrm{~N}$-doped graphene anodes for high-rate and lasting lithium storage. J. Alloys Compounds 769, 1007-1018. doi: 10.1016/j.jallcom.2018.08.038

Liu, J., Li, W., and Manthiram, A. (2010). Dense core-shell structured $\mathrm{SnO}_{2} / \mathrm{C}$ composites as high performance anodes for lithium ion batteries. Chem. Commun. 46, 1437-1439. doi: 10.1039/b918501a

Liu, Z., Cao, Z., Deng, B., Wang, Y., Shao, J., Kumar, P., et al. (2014). Ultrafast and scalable laser liquid synthesis of tin oxide nanotubes and its application in lithium ion batteries. Nanoscale 6, 5853-5858. doi: 10.1039/C3NR06444A

Lu, X., Liu, D., Han, T., Zhu, M., Ryu, S. O., and Huang, J. (2018). A facile synthesis of sandwich-structured $\mathrm{SnS}_{2} @$ reduced graphene oxide with high performance for lithium-ion battery anode. J. Alloys Compounds 765, 1061-1071. doi: 10.1016/j.jallcom.2018.06.245

Ren, W., Liu, D., Sun, C., Yao, X., Tan, J., Wang, C., et al. (2018). Nonhierarchical heterostructured $\mathrm{Fe}_{2} \mathrm{O}_{3} / \mathrm{Mn}_{2} \mathrm{O}_{3}$ porous hollow spheres for enhanced lithium storage. Small 14:1800659. doi: 10.1002/smll.201800659

Sahoo, M., and Ramaprabhu, S. (2018). One-pot environment-friendly synthesis of boron doped graphene- $\mathrm{SnO}_{2}$ for anodic performance in Li ion battery. Carbon 127, 627-635. doi: 10.1016/j.carbon.2017.11.056

Shah, M. S., a. S., Lee, J., Park, A. R., Choi, Y., Kim, W.-J., et al. (2017). Ultrafine $\mathrm{SnO}_{2}$ nanoparticles doubly embedded in amorphous carbon and reduced graphene oxide (rGO) for superior lithium storage. Electrochim. Acta 224, 201-210. doi: 10.1016/j.electacta.2016.12.049

Shan, J., Liu, Y., Liu, P., Huang, Y., Su, Y., Wu, D., et al. (2015). Nitrogendoped carbon-encapsulated $\mathrm{SnO}_{2}$-SnS/graphene sheets with improved anodic performance in lithium ion batteries. J. Mater. Chem. A 3, 24148-24154. doi: 10.1039/C5TA06617D

Shao, Q., Tang, J., Sun, Y., Li, J., Zhang, K., Yuan, J., et al. (2017). Unique interconnected graphene/ $\mathrm{SnO}_{2}$ nanoparticle spherical multilayers for lithiumion battery applications. Nanoscale 9, 4439-4444. doi: 10.1039/C6NR09689A

Shi, W., and Lu, B. (2014). Nanoscale Kirkendall effect synthesis of echinus-like $\mathrm{SnO}_{2} @ \mathrm{SnS}_{2}$ nanospheres as high performance anode material for lithium ion batteries. Electrochim. Acta 133, 247-253. doi: 10.1016/j.electacta.2014.04.013

Tong, H., Dong, P., Zhang, J., Zheng, J., Yu, W., Wei, K., et al. (2018). Cathode material $\mathrm{LiNi}_{0.8} \mathrm{Co}_{0.1} \mathrm{Mn}_{0.1} \mathrm{O}_{2} / \mathrm{LaPO}_{4}$ with high electrochemical performance for lithium-ion batteries. J. Alloys Compounds 764, 44-50. doi: 10.1016/j.jallcom.2018.06.020

Tong, H., Zhou, Q., Zhang, B., Wang, X., Yao, Y., Ding, Z., et al. (2019). A novel core-shell structured nickel-rich layered cathode material for high-energy lithium-ion batteries. Eng. Sci. doi: 10.30919/es8d502

Wang, G., Xiong, X., Xie, D., Fu, X., Ma, X., Li, Y., et al. (2019). Suppressing dendrite growth by a functional electrolyte additive for robust Li metal anodes. Energy Storage Mater. doi: 10.1016/j.ensm.2019. 02.026

Wang, H., Jiang, X., Chai, Y., Yang, X., and Yuan, R. (2018). Sandwichlike $\mathrm{C} @ \mathrm{SnO}_{2} / \mathrm{Sn} /$ void@C hollow spheres as improved anode materials for lithium ion batteries. J. Power Sources 379, 191-196. doi: 10.1016/j.jpowsour.2018.01.054 
Wang, L., Wang, D., Dong, Z., Zhang, F., and Jin, J. (2013). Interface chemistry engineering for stable cycling of reduced $\mathrm{GO} / \mathrm{SnO}_{2}$ nanocomposites for lithium ion battery. Nano Lett. 13, 1711-1716. doi: 10.1021/nl400269d

Wang, R., Li, X., Wang, Z., and Han, Z. (2017a). Electrochemical analysis graphite/electrolyte interface in lithium-ion batteries: pToluenesulfonyl isocyanate as electrolyte additive. Nano Energy 34, 131-140. doi: 10.1016/j.nanoen.2017.02.037

Wang, R., Wang, Z., Li, X., and Han, Z. (2017b). Electrochemical analysis the influence of Propargyl Methanesulfonate as electrolyte additive for spinel LTO interface layer. Electrochim. Acta 241, 208-219. doi: 10.1016/j.electacta.2017.04.125

Woo, H., Wi, S., Kim, J., Kim, J., Lee, S., Hwang, T., et al. (2018). Complementary surface modification by disordered carbon and reduced graphene oxide on $\mathrm{SnO}_{2}$ hollow spheres as an anode for Li-ion battery. Carbon 129, 342-348. doi: 10.1016/j.carbon.2017.12.015

Wu, L., Zheng, J., Wang, L., Xiong, X., Shao, Y., Wang, G., et al. (2019). PPyencapsulated $\mathrm{SnS}_{2}$ nanosheets stabilized by defects on a $\mathrm{TiO}_{2}$ support as a durable anode material for lithium-ion batteries. Angew. Chem. Int. Ed. 58, 811-815. doi: 10.1002/anie.201811784

Wu, N., Du, W., Gao, X., Zhao, L., Liu, G., Liu, X., et al. (2018). Hollow $\mathrm{SnO}_{2}$ nanospheres with oxygen vacancies entrapped by a N-doped graphene network as robust anode materials for lithium-ion batteries. Nanoscale 10, 11460-11466. doi: 10.1039/C8NR02290A

Xiao, B., Zhang, B., Zheng, J.-C., Tang, L.-B., An, C.-S., He, Z.-J., et al. (2018). Nano-micro structure $\mathrm{VO}_{2} / \mathrm{CNTs}$ composite as a potential anode material for lithium ion batteries. Ceramics Int. 44, 13113-13121. doi: 10.1016/j.ceramint.2018.04.133

Xu, K., Li, N., Zeng, D., Tian, S., Zhang, S., Hu, D., et al. (2015). Interface bonds determined gas-sensing of $\mathrm{SnO}_{2}-\mathrm{SnS}_{2}$ hybrids to ammonia at room temperature. ACS Appl. Mater. Interfaces 7, 11359-11368. doi: $10.1021 /$ acsami.5b01856

Yang, J., Chen, S., Tang, J., Tian, H., Bai, T., and Zhou, X. (2018). Rodlike hierarchical Sn/SnO $\mathrm{S}_{\mathrm{x}} @ \mathrm{C}$ nanostructures with enhanced lithium storage properties. Appl. Surface Sci. 435, 203-209. doi: 10.1016/j.apsusc.2017. 11.085

Ye, X., Lin, Z., Liang, S., Huang, X., Qiu, X., Qiu, Y., et al. (2019). Upcycling of electroplating sludge into ultrafine Sn@C nanorods with highly stable lithium storage performance. Nano Lett. 19, 1860-1866. doi: 10.1021/acs.nanolett.8b 04944

Yi, L., Liu, L., Guo, G., Chen, X., Zhang, Y., Yu, S., et al. (2017). Expanded graphite@SnO $2 @$ polyaniline composite with enhanced performance as anode materials for lithium ion batteries. Electrochim. Acta 240, 63-71. doi: 10.1016/j.electacta.2017. 04.012
Yin, L., Chai, S., Huang, J., Kong, X., and Pan, L. (2017). Preparation of hierarchical $\mathrm{SnS}_{2} / \mathrm{SnO}_{2}$ anode with enhanced electrochemical performances for lithium-ion battery. Electrochim. Acta 238, 168-177. doi: 10.1016/j.electacta.2017.03.183

Ying, H., and Han, W. Q. (2017). Metallic Sn-based anode materials: application in high-performance lithium-ion and sodium-ion batteries. Adv. Sci. 4:1700298. doi: 10.1002/advs.201700298

Zhang, B., Dong, P., Tong, H., Yao, Y., Zheng, J., Yu, W., et al. (2017). Enhanced electrochemical performance of $\mathrm{LiNi}_{0.8} \mathrm{Co}_{0.1} \mathrm{Mn}_{0.1} \mathrm{O}_{2}$ with lithium-reactive $\mathrm{Li}_{3} \mathrm{VO}_{4}$ coating. J. Alloys Compounds 706, 198-204. doi: 10.1016/j.jallcom.2017.02.224

Zhang, M., Sun, Z., Zhang, T., Sui, D., Ma, Y., and Chen, Y. (2016). Excellent cycling stability with high $\mathrm{SnO}_{2}$ loading on a three-dimensional graphene network for lithium ion batteries. Carbon 102, 32-38. doi: 10.1016/j.carbon.2016.02.032

Zhang, S., Zhao, H., Yue, L., Wang, Z., and Mi, J. (2017). Fixedbed assisted synthesis $\mathrm{SnO}_{2} / \mathrm{SnS}_{2} / \mathrm{CNTs}$ composite for enhanced sodium storage performance. J. Alloys Compounds 717, 127-135. doi: 10.1016/j.jallcom.2017.05.055

Zhang, Y., Yang, J., Zhang, Y., Li, C., Huang, W., Yan, Q., et al. (2018). $\mathrm{Fe}_{2} \mathrm{O}_{3} / \mathrm{SnSSe}$ hexagonal nanoplates as lithium-ion batteries anode. ACS Appl. Mater. Interfaces 10, 12722-12730. doi: 10.1021/acsami.8b01537

Zhao, C., Yu, C., Zhang, M., Sun, Q., Li, S., Banis, M. N., et al. (2017) Enhanced sodium storage capability enabled by super wide-interlayerspacing $\mathrm{MoS}_{2}$ integrated on carbon fibers. Nano Energy 41, 66-74. doi: 10.1016/j.nanoen.2017.08.030

Zheng, J.-C., Yang, Z., He, Z.-J., Tong, H., Yu, W.-J., and Zhang, J.-F. (2018). In situ formed $\mathrm{LiNi}_{0.8} \mathrm{Co}_{0.15} \mathrm{Al}_{0.05} \mathrm{O}_{2} @ \mathrm{Li}_{4} \mathrm{SiO}_{4}$ composite cathode material with high rate capability and long cycling stability for lithium-ion batteries. Nano Energy 53, 613-621. doi: 10.1016/j.nanoen.2018.09.014

Zhou, X., Wan, L. J., and Guo, Y. G. (2013). Binding $\mathrm{SnO}_{2}$ nanocrystals in nitrogen-doped graphene sheets as anode materials for lithium-ion batteries. Adv. Mater. 25, 2152-2157. doi: 10.1002/adma.201300071

Conflict of Interest Statement: The authors declare that the research was conducted in the absence of any commercial or financial relationships that could be construed as a potential conflict of interest.

Copyright (c) 2019 Li, Zhang, Wang, Zhang, An, Ding, Yu and Tong. This is an open-access article distributed under the terms of the Creative Commons Attribution License (CC BY). The use, distribution or reproduction in other forums is permitted, provided the original author(s) and the copyright owner(s) are credited and that the original publication in this journal is cited, in accordance with accepted academic practice. No use, distribution or reproduction is permitted which does not comply with these terms. 